\title{
PENGARUH DURASI CAMSHAFT TERHADAP PRESTASI MESIN BENSIN 110 CC
}

\author{
Halim $^{1}$, Reza Bachmid ${ }^{2}$, Sabda Purna Yudha ${ }^{3}$ \\ 1,2Jurusan Teknik Alat Berat, ${ }^{3}$ Jurusan Teknik Manufaktur, Politeknik Batulicin, Jl. Lingkar 30, Kecamatan Batulicin, \\ Kabupaten Tanah Bumbu, Propinsi Kalimantan Selatan. \\ halimrahimst@gmail.com
}

\begin{abstract}
Abstrak - Pengaruh durasi camshaft terhadap prestasi mesin bensin $110 \mathrm{cc}$ dilakukan dengan membandingkan durasi camshaft standar dan modifikasi sebesar durasi $303.5^{\circ}$ sehingga diperoleh tenaga maksimal yang dihasilkan mesin suzuki tipe smash $110 \mathrm{cc}$ dan pengaruhnya terhadap penggunaan konsumsi bahan bakar. Penelitian ini bertujuan (1) mengetahui daya, torsi mesin dengan modifikasi pada durasi camshaft, (2) mengetahui jumlah konsumsi bahan bakar (FC), (SFC), dan efisiensi termal mesin standar dengan mesin telah dimodifikasi pada durasi camshaftnya. Metode pengujian dalam penelitian dilakukan dengan chasis dinamometer adapun pengujian dilakukan di PT. Suzuki Galesong Pratama dengan mengikuti standar pengujian Suzuki yang telah ditetapkan. Hasil penelitian menunjukkan terjadi perubahan nilai daya dan torsi pada mesin standar daya yang diperoleh sebesar 5,3 HP atau 3,88 $\mathrm{kW}$ sampai $6,0 \mathrm{HP}$ atau 4,63 $\mathrm{kW}$ dengan nilai torsi $6,14 \mathrm{Nm}$, kemudian menurun pada putaran $9000 \mathrm{rpm}$ sebesar $5.02 \mathrm{Nm}$. Sementara durasi camshaft modifikasi daya yang diperoleh sebesar 7,5 HP atau 5,60 kW dengan torsi 8,65 Nm juga mengalami penurunan pada putaran $9000 \mathrm{rpm}$ sebesar 7,9 HP atau 5,89 kW. Adapun pengaruh yang signifikan terjadi pada putaran $9000 \mathrm{rpm}$. Nilai FC camshaft standar diperoleh sebesar $0,8946 \mathrm{~kg} / \mathrm{h}, \mathrm{SFC}=0,1932 \mathrm{~kg} / \mathrm{kWh}$. Untuk durasi camshaft modifikasi, pada putaran $9000 \mathrm{rpm}$ nilai FC yang diperoleh sebesar $1,6526 \mathrm{~kg} / \mathrm{h}, \mathrm{SFC}=0,2806 \mathrm{~kg} / \mathrm{kWh}$ dari hasil tersebut diketahui peningkatan terjadi pada nilai $\mathrm{FC}$ dengan selisih sebesar 0,758 dari hasil sebelumnya dengan SFC sebesar 0,0874. Selanjutnya efisiensi termal diperoleh sebesar 50,01 \% pada putaran $6000 \mathrm{rpm}$ kemudian menurun sebesar 40,29\% pada putaran $9000 \mathrm{rpm}$ untuk camshaft standar, untuk durasi camshaft modifikasi diperoleh sebesar 53,34\% pada putaran $6000 \mathrm{rpm}$ dan menurun sebesar 30,02\% pada putaran $9000 \mathrm{rpm}$.
\end{abstract}

Kata Kunci- durasi camshaft, durastasi mesin bensin, konsumsi bahan bakar.

\begin{abstract}
Effect camshaft duration on performance of 110 cc gasoline engine carried out by comparing the duration of standard and modified camshafts of $303.5^{\circ}$ to obtain maximum power produced by $110 \mathrm{cc}$ smash type Suzuki engine and its effect on fuel consumption. This study aims to know of, (1) torque machine with modification in duration camshaft, (2) knowing total fuel consumption (FC), spesific fuel consumption (SFC), and thermal efficiency of the standard engine and engine has modified in the duration of its camshaft. A method of testing in the research was done with to the chassis of dynamometer as for testing done in PT.Suzuki galesong pratama through adhering to a standard testing suzuki that has been set. The results showed a change in the value of power and torque on standard engine power obtained by $5.3 \mathrm{HP}$ or $3.88 \mathrm{~kW}$ to $6.0 \mathrm{HP}$ or $4.63 \mathrm{~kW}$ with a torque value of $6.14 \mathrm{~N} . \mathrm{m}$, then decreased at $9000 \mathrm{rpm}$ rotation of $5.02 \mathrm{Nm}$. While the duration of power modification camshaft obtained is $7.5 \mathrm{HP}$ or $5.60 \mathrm{~kW}$ with a torque of $8.65 \mathrm{Nm}$, it also decreases at $9000 \mathrm{rpm}$ of $7.9 \mathrm{HP}$ or $5.89 \mathrm{~kW}$. The significant effect occurs at $9000 \mathrm{rpm}$. Standard camshaft FC value is obtained at $0.8946 \mathrm{~kg} / \mathrm{h}, S F C=0.1932 \mathrm{~kg} / \mathrm{kWh}$. For duration of modified camshaft, at $9000 \mathrm{rpm}$, FC value obtained was $1.6526 \mathrm{~kg} / \mathrm{h}, \mathrm{SFC}=0.2806 \mathrm{~kg} / \mathrm{kWh}$. From these results, it is known that an increase occurred in the FC value with a difference of 0.758 from previous results with an SFC of 0.0874. Furthermore, thermal efficiency obtained by $50.01 \%$ at $6000 \mathrm{rpm}$ decrease by $40.29 \%$ at $9000 \mathrm{rpm}$ for standard camshaft. The duration of a modified camshaft was obtained by $53.34 \%$ at 6000 rpm and decrease by $30.02 \%$ at 9000 rpm..
\end{abstract}

Keywords - camshaft duration, gasoline engine performance, fuel consumption.

\section{PENDAHULUAN}

Alat transportasi belakangan yang semakin populer dan jumlahnya semakin bertambah adalah sepeda motor, saat ini sepeda motor menjadi barang yang sangat dibutuhkan. Mobilitas yang tinggi dan tingkat kepadatan menjadi penyebab, mengapa penggunaan sepeda motor menjadi sangat populer. Tingginya angka permintaan masyarakat membuat munculnya berbagai tipe sepeda motor dari bermacam merek yang ditawarkan oleh kompetitor untuk menarik pengguna sepeda motor.
Salah satu hal yang menarik banyak bermunculan berbagai macam jenis kendaraan yang memiliki spesifikasi masingmasing sehingga para pengguna berlomba dalam melakukan modifikasi, baik itu modifikasi pada bagian rangka (frame) ataupun modifikasi yang dilakukan pada bagian mesin (engine) untuk menunjang aktifitas sepeda motor dalam penggunaan sehari-hari, ataupun yang berkaitan dengan peningkatan prestasi mesin mesin sepeda motor.

Untuk modifikasi pada bagian kepala silinder cara yang ditempuh, antara lain dengan melakukan desain pada porting yaitu saluran masuk dan buang yang diperbesar untuk mendapatkan jumlah bahan bakar yang banyak, perancangan 
ulang ruang bakar, memperluas ruang venturi karburator, perancangan ulang pada katup masuk dan katup buang dan banyak hal yang mampu dilakukan. Dengan kata lain, hal tersebut bertujuan untuk meningkatkan prestasi mesin, dimana dengan penambahan konsumsi bahan bakar diharapkan mampu memberikan tenaga maksimal, salah satu metode yang dilakukan adalah dengan me-modifikasi pada derajat camshaft

Penelitian tentang pengaruh durasi camshaft pada dasarnya sudah dilakukan. Dalam penelitiannya Firman Iffah Darmawangsa dan Bambang Sudarmanta [1], menganalisa perubahan durasi camshaft terhadap prestasi dan emisi gas buang pada mesin sinjai $650 \mathrm{cc}$, penelitian yang dilakukan menggunakan simulasi software Lotus Engine Simulation (LES), hasil menunjukkan simulasi menggunakan LES dengan engine tipe sinjai $650 \mathrm{cc}$ SOHC jenis injeksi port, dihasilkan durasi terbaik $260^{\circ}$ pada derajat camshaft dengan kecepatan tinggi. Kemudian hasil lainnya diperoleh kenaikan sebesar $\quad 0.908 \%$ untuk torsi, 0,908 \% daya, 0,908\% bmep, $0,626 \%$ efisiensi termal, efisiensi volumetris $1.003 \%$ dan terjadi penurunan pada bsfc sebesar 0,252 \%, dari camshaft standar $248^{\circ}$ pada putaran tinggi. Penelitian lainnya juga dilakukan oleh Fransiskus Xaverius Sukidjo [2] meneliti tentang pengaruh durasi camshaft terhadap emisi gas buang, penggunaan bahan bakar, torsi dan daya mesin pada mesin bensin dari penelitian tersebut disimpulkan terjadi penggunaan bahan bakar lebih banyak sebesar 3,32 mililiter/HP.jam pada durasi $210^{\circ}$ dibandingkan pada durasi $290^{\circ}$ sebesar 5,48 mililiter/HP.jam, dan konsentrasi CO, HC kemudian terjadi penurunan di putaran tinggi yaitu pada rpm 7000 sampai rpm 10000. Penelitian lainnya yang penting juga dilakukan oleh Dwi Kristianto, dkk [3], pengaruh perubahan durasi camshaft terhadap performance mesin FD $110 \mathrm{cc}$, penelitian ini menyimpulkan pengaruh yang penting terhadap unjuk kerja motor bensin jenis Shogun FD 110 cc pengujian dilakukan dengan putaran mesin $10000 \mathrm{rpm}$ yaitu: pada torsi, daya efektif, daya mekanis, tekanan efektif, tekanan mekanis, dan pemakaian bahan bakar. Besar sudut durasi camshaft yang digunakan $263^{\circ}$. Dari hasil penelitian tersebut diperoleh hasil sebagai berikut: torsi $0,8425 \mathrm{~kg} . \mathrm{m}$, dan daya efektif 11.7634 Hp. Sementara untuk durasi $270^{\circ}$ adanya peningkatan torsi yang terjadi sebesar 0,9282 kg.m, kemudian daya efektif sebesar 12,96005 Hp. Hasil dari penelitian yang dilakukan tersebut berdasarkan pengujian durasi standar dengan torsi 0,571 kg.m, dan daya efektif sebesar 7,97 Hp. Sementara Octanius Dwi Prakoso dan Wahyudi [4], penelitian yang dilakukan yaitu penggunaan variasi camshaft terhadap performa mesin motor 4 langkah menunjukkan bahwa pada durasi $210^{\circ}$. dari penelitian dilakukan diperoleh torsi sebesar $7,53 \mathrm{Nm}$ pada putaran $4000 \mathrm{rpm}$, sfc sebesar $0,041 \mathrm{~kg} /$ $\mathrm{kW}$.jam, dengan daya sebesar $3,98 \mathrm{~kW}$ pada $8000 \mathrm{rpm}$. Adapun pada durasi $231^{\circ}$ torsi yang diperoleh sebesar 5.96 $\mathrm{Nm}$, dengan $\mathrm{sfc}$ terendah $0,084 \mathrm{~kg} / \mathrm{Kw} . J a m$ putaran 5000 $\mathrm{rpm}$, sementara daya diperoleh sebesar $4,80 \mathrm{~kW}$ pada putaran $8000 \mathrm{rpm}$. Sedangkan pada durasi $238^{\circ}$ putaran $5000 \mathrm{rpm}$ terjadi peningkatan torsi dari sebelumnya sebesar 7,43 N.m dengan sfc sebesar 0,068 kg / kW.Jam, dan daya sebesar 4,20 kW pada $8000 \mathrm{rpm}$.
Dari beberapa penelitian diatas menujukkan bahwa durasi camshaft terhadap konsumsi bahan bakar merupakan pengaruh yang penting. Pada penelitian ini dilakukan pengaruh durasi camshaft terhadap konsumsi bahan bakar mesin Suzuki tipe smash 110 cc. Camshaft berperan sebagai pengatur buka tutup katup masuk dan buang. sehingga gas pembakaran dari saluran masuk dan sisa pembakaran bergantung pada saat buka tutup yang diatur oleh tinggi angkat camshaft. Untuk menghasilkan tenaga yang besar dari sebuah mesin adalah meningkatkan operasi volumetrik sebesar-besarnya, yaitu memasukkan pencampuran udara dan bahan bakar sebanyak-banyaknya ke dalam ruang bahan bakar dan mengeluarkan gas sisa pembakaran selancar-lancarnya dalam proses pembakaran yang sempurna. Dengan modifikasi camshaft, maka dapat ditentukan perubahan daya (BHP) dan torsi antara mesin standar yang dihasilkan setelah melakukan modifikasi pada durasi camshaft dan besar perubahan penggunaan spesifik bahan bakar (SFC) antara mesin standar dan setelah melakukan modifikasi, sehingga hasil yang diperoleh dapat memberikan kontribusi bagi pengguna sepeda motor pada umumnya dan kompetitor Suzuki pada khususnya.

Penelitian ini difokuskan pada modifikasi derajat camshaft $303,5^{\circ}$, dengan membandingkan antara kondisi standarnya. Konsumsi bahan bakar dibuat terlebih dahulu menggunakan penampungan kapasitas $1000 \mathrm{ml}$, selanjutnya memodifikasi camshaft menggunakan camshaft yang baru. Hasil dari modifikasi camshaft dilakukan pengecekan kembali kemudian dipasangkan pada kendaraan, yang diukur dengan busur derajat dan berpatokan pada putaran camshaft, proses berlangsung berulang kali untuk memperoleh hasil yang valid dan reliable.

Tujuan penulisan ini mengevaluasi camshaft antara modifikasi dan standar, mengevaluasi daya, torsi, efisiensi termal, fc, dan konsumsi bahan bakar spesifik (sfc).

Penelitian ini diharapkan dapat memberikan kontribusi bagi pengguna sepeda motor umum dalam pengetahuan mengenai camshaft sebagai sarana informasi dalam me-modifikasi camshaft untuk kompetitor pada khususnya.

\section{FUNDAMENTAL}

Camshaft merupakan pengatur waktu buka tutup katup masuk dan buang. Menurut Des Hammill, bagian-bagian lobe dari sebuah camshaft yang harus ditentukan, sebab lobe dipisah dari bidang yang berbeda diantara bagian dari bidangnya yaitu: hidung (nose), tumit (heel), sayap (flanks), titik waktu buka-tutup (opening and closing ramps), lingkaran dasar (base circle) [5]. Dalam penelitian Ardianto Argo Busono [6], melakukan modifikasi pada unjuk kerja sepeda motor Honda tipe GL 100, hasil dari penelitian yang dilakukan menunjukkan intake manifold porting pada piston racing dan standar mampu menghasilkan torsi dan daya tinggi pada putaran bawah kemudian di putaran atas terjadi perubahan dengan bertambahnya penggunaan bahan bakar. Namun diperoleh penggunaan bahan bakar yang rendah untuk manifold jenis racing pada putaran $5000 \mathrm{rpm}$ dibandaingkan dengan penggunaan pada jenis standar [7].

Mengganti camshaft merupakan cara termudah untuk menaikkan tenaga dan mesin. Apabila salah dalam memilih 
menyebabkan tenaga akan turun dan konsumsi bahan bakar menjadi tidak efisien. Menurut Des Hammil, kisaran durasi camshaft yang penting untuk mesin performa tinggi yaitu antara $270^{\circ}-310^{\circ}$. Dengan pengujian telah dibuktikan bahwa secara umum aplikasi durasi antara $270^{\circ}$ dan $310^{\circ}$ merupakan durasi yang paling sesuai untuk kebutuhan race (kompetisi). Perbedaan $40^{\circ}$ antara durasi $270^{\circ}$ dan $310^{\circ}$ kelihatannya sangat kecil, akan tetapi dalam prakteknya membuat banyak sekali perbedaan. klasifikasi lima tipe durasi camshaft, yaitu: camshaft durasi $270^{\circ}, 280^{\circ}, 290^{\circ}, 300^{\circ}$ dan $310^{\circ}$. Sebagai contoh camshaft dengan durasi $272^{\circ}$ adalah masuk dalam kategori durasi $270^{\circ}$ karena efek yang dirasakan pada mesin dapat dikatakan dengan efek durasi $270^{\circ}$. Begitu pula camshaft dengan durasi $288^{\circ}$ termasuk dalam durasi $290^{\circ}$, karena efek pada mesin dapat dikatakan sama dengan durasi $290^{\circ}$. Selanjutnya, Des Hammill (1998) juga menambahkan bahwa 2 camshaft dengan durasi yang sama bisa berbeda karena adanya perbedaan phassing yang terjadi. sehingga efek yang terjadi pada mesin menjadi berbeda [5]. Dalam memodifikasi camshaft ada beberapa istilah yang perlu untuk dipakai. Istilah-istilah tersebut menurut Poter Burgess (2000), yaitu : Durasi (durationi), phasing, valve lift, camshaft lobe lift, overlap, lift rate, valve clereance, full lift, piston to valve cleareance dan camshaft profile [8].

Mesin 4 tak/langkah (Four stroke engine) merupakan mesin yang menghasilkan tenaga dengan empat proses langkah naik dan turun ring piston, yakni dua kali rotasi pada kruk as, dan satu putaran noken as (camshaft). Dari langkah tersebut diuraikan sebagai berikut, langkah isap (suction stroke), langkah kompresi (compression stroke), langkah usaha (power stroke), langkah buang (exhaust stroke) [9].

Konsumsi bahan bakar merupakan jumlah volume atau berat jenis bahan bakar yang terbakar tiap menitnya, yaitu pencampuran antara udara dan bahan bakar didalam karburator, kemudian saat masuk ke dalam silinder yang berupa pencampuran antara udara dan bahan bakar (fuel-air mixture). Kalor yang dihasilkan pada proses pembakaran dari campuran tersebut dalam ruang bakar, yang kemudian diubah menjadi energi mekanik pada poros engkol mesin. Dengan memperbesar overlap maka dapat memasukan campuran udara dan bahan bakar sebanyak mungkin, yang berarti memperbesar efisiensi volumetrik. Tetapi katup masuk dan buang yang terbuka terlalu lama dapat mengurangi tekanan di dalam silinder. dan dapat mengurangi kandungan nitrogen oksida [10].

Daya diperoleh melalui perubahan energi kimia atau nilai kalor bahan bakar yang dihasilkan. Makin banyak bahan bakar yang mampu dibakar, makin besar daya yang dihasilkan. Hal tersebut dapat dipenuhi jika tersedia udara secukupnya dalam silinder. Sementara durasi camshaft merupakan berapa lama waktu cam menjaga katup tetap membuka dan dinyatakan dalam derajat rotasi poros engkol. Pada saat putaran tinggi, jumlah banyaknya udara dan bahan bakar yang masuk tidak sebanyak saat putaran rendah. Hal ini disebabkan katup masuk membuka dan menutup lebih cepat dalam satuan mili detik [11].

Persamaan yang digunakan untuk menghitung prestasi mesin besin yaitu dengan prosedur sebagai berikut,

\section{Persamaan (1) konsumsi bahan bakar (fc)}

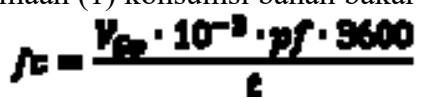

Dimana : FC merupakan konsumsi bahan bakar $(\mathrm{kg} / \mathrm{h})$, VGU adalah volume gelas ukur (ml), pf massa jenis bensin $(\mathrm{kg} / \mathrm{L}), \mathrm{t}$ waktu (jam) [12].

Untuk menghitung penggunaan bahan bakar spesifik dengan menggunakan persamaan (2) sebagai berikut:

\section{$y=\frac{f e}{B f p}$}

Dimana : SFC adalah penggunaan bahan bakar spesifik $(\mathrm{kg} / \mathrm{kWh})$, BHP adalah daya poros $(\mathrm{kW})$ [13].

Untuk mengetahui efisiensi termal, terlebih dahulu diketahui kalor total pada sebuah mesin, dengan menggunakan persamaan (3) sebagai berikut:

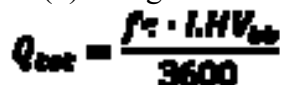

Dimana: Qtot adalah kalor total bahan bakar $(\mathrm{kW})$, LHVbb yaitu nilai kalor pembakaran $(\mathrm{kJ} / \mathrm{kg})$ [14].

Sehingga efisiensi termal ( $\eta$ th) dapat diperoleh dengan menggunakan persamaan (4) berikut:

\section{Nit $=\frac{B H P}{a_{m}} \times 100 \mathrm{~m}$}

Dimana: $\eta$ th adalah efisiensi termal, BHP adalah daya poros $(\mathrm{kW})[15]$.

\section{METODE}

Camshaft berperan sebagai pengatur buka tutup katup masuk dan buang pada kepala silinder. Dengan demikian total bahan bakar yang masuk dan yang keluar bergantung pada kondisi buka tutup klep masuk dan keluar yang diatur oleh durasi dan tinggi angkat camshaft.

Pada pengujian ini, perubahan durasi camshaft dengan membandingkan durasi camshaft standar dan durasi camshaft dimodifikasi sehingga diperoleh tenaga maksimal dihasilkan oleh mesin suzuki tipe smash $110 \mathrm{cc}$ dan dampak terhadap daya, torsi, penggunaan komsumsi bahan bakar dan efisiensi termal setelah mengalami perubahan durasi pada camshaft. Berikut gambar camshaft modifikasi yang digunakan pada penelitian

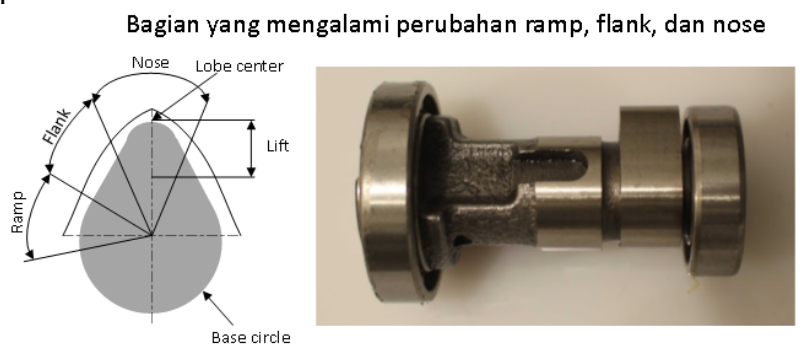

Gambar 1 camshaft modifikasi yang digunakan dalam penelitian

Penelitian dilakukan dengan tahapan memodifikasi camshaft menggunakan camshaft yang baru dengan cara melakukan troubleshooting terlebih dahulu pada bagian kepala silinder untuk mengganti camshaft yang lama dan melakukan 
pembersihan pada bagian kepala silinder dari karbon sisa pembakaran yang berada pada permukaan piston agar proses pengujian tidak berpengaruh oleh faktor lain disebabkan karbon yang menempel pada permukaan piston. Selanjutnya modifikasi pada durasi camshaft. Modifikasi durasi camshaft dikerjakan dengan menggunakan alat modifikasi camshaft. Alat modifikasi merupakan sebuah gerinda untuk mengubah bentuk profil, durasi, tinggi angkat dan segala yang berhubungan dengan fungsi camshaft. Alat ini terdiri dari mata gerinda kasar yang berfungsi untuk mengikis bagian material camshaft sama banyak, yang kemudian hasil akhir dilakukan pada mata gerinda yang lain (lebih halus) agar diperoleh hasil yang presisi. Metode pengujian dalam penelitian ini menggunakan metode chasis dynamometer.

Prosedur yang dilakukan dalam mengukur daya mesin menggunakan dynotest dan prosedur pengambilan data pengujian konsumsi bahan bakar sebagai berikut:

Pengujian dynotest dilakukan dengan tahapan berikut ini:

1. Pengecekan awal dilakukan terlebih dahulu pada minyak pelumas, kemudian pada penyetelan roda, dan tekanan udara ban.

2. Menyalakan PC lalu memasukkan input data temperatur dan kelembaban udara. Kemudian mengatur penyimpanan folder untuk data dynotest saat pengujian.

3. Memposisikan motor keatas alat dynotest kemudian menyesuaikan roda agar segaris dengan poros roller

4. Kabel sensor untuk pembacaaan putaran dihubungkan pada kabel koil. Selanjutnya sabuk pengencang frame dipasang pada frame depan motor dan sisi lainnya dikunci pada body dynotest. Setelah dipasang, lalu dikencangkan dan proses pengencangan kiri dan kanan harus seimbang dan posisi motor harus dalam keadaan tegak.

4. Mesin motor dalam posisi on kemudian dibiarkan bertujuan agar mesin mencapai temperatur stedi.

5. Memposisikan komputer dan program dalam keadaan siap.

6. Mengoprasikan motor pada gigi 3, kemudian menaikkan putaran sampai menyentuh angka $6000 \mathrm{rpm}$ konstan.

7. Ketika tombol start ditekan menandakan bahwa program PC mulai melakukan proses pencatatan grafik sehingga penekanan tombol start secara bersamaan dengan operator yang membuka throtle.

8. Setelah motor mencapai kemampuan maksimumnya, segera tombol start ditekan kembali. Selanjutnya hasil dapat dilihat pada monitor berupa data grafik dan tabel.

Prosedur pengujian konsumsi bahan bakar dilakukan dengan langka-langkah berikut:

1. Mempersiapkan alat uji konsumsi bahan bakar.

2. Menghubungkan selang keluaran alat kedalam saluran bensin pada karburator, penelitian menggunakan selang ukuran $40 \mathrm{ml}$ dalam pengujian komsumsi bahan bakar.

3. Membuka katup saluran bahan bakar yang menuju saluran keluaran.

4. Motor dalam posisi on pada dynotest dengan memanfaatkan rpmnya saja.

5. Mengoprasikan motor pada gigi 3 kemudian membuka throtle motor sampai putaran mesin menujukkan $6000 \mathrm{rpm}$.
6. Ketika sudah mencapai $6000 \mathrm{rpm}$, saluran saluran untuk komsumsi bahan bakar diaktifkan sehingga mesin menyedot bahan bakar $10 \mathrm{ml}$.

7. Pencatatan waktu komsumsi bahan bakar per $10 \mathrm{ml}$ dimulai dengan menggunakan stopwatch.

8. Melakukan langkah 3 sampai langkah 8 untuk putaran mesin selanjutnya ( $6000 \mathrm{rpm}, 7000 \mathrm{rpm}, 8000 \mathrm{rpm}$ ).

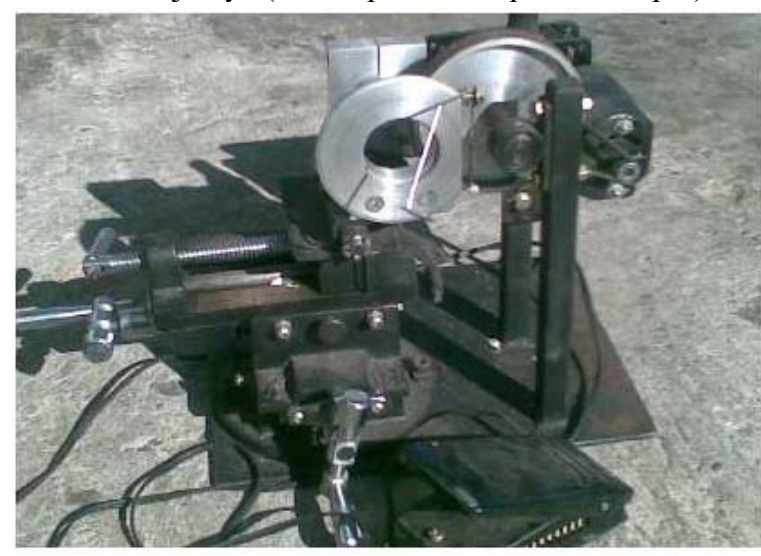

Gambar 2 Alat modifikasi camshaft

Berikut adalah gambar bagian-bagian dari proses pengujian alat yang dilakukan
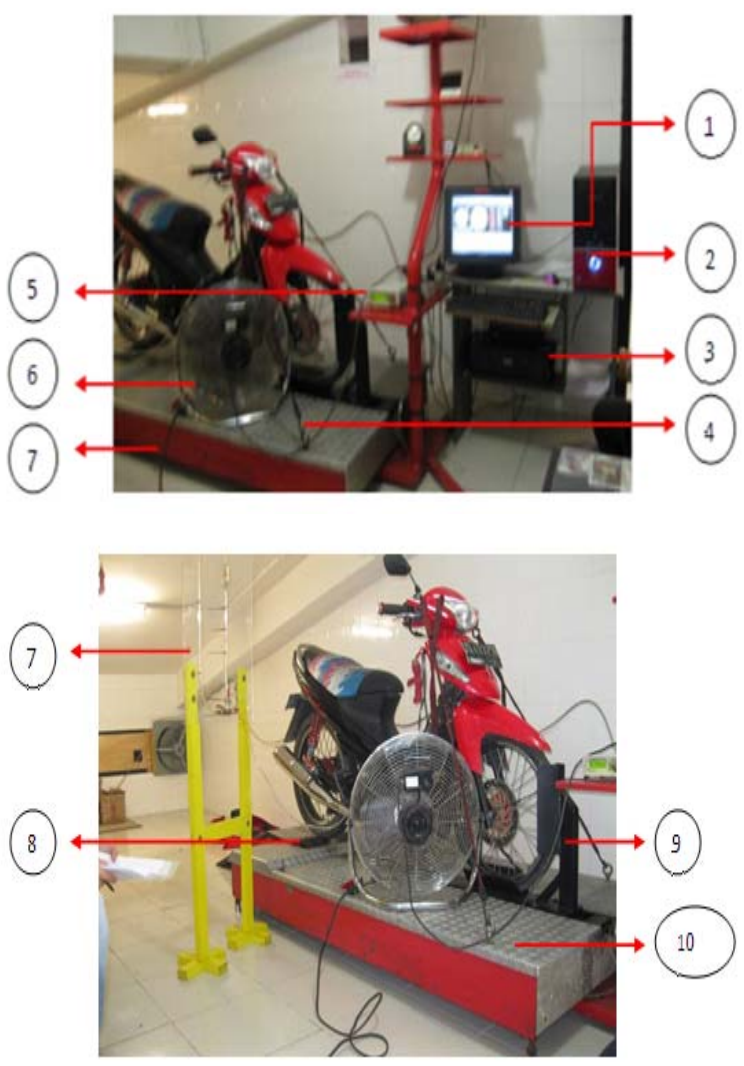

Gambar 3 Inertia chassis dynamometer (Dynotest) 
Keterangan gambar:

1. Monitor PC.

2. Cpu unit.

3. Printer.

4. Sabuk pengencang.

5. Higrometer.

6. Kipas pendingin.

7. Alat uji konsumsi bahan bakar.

8. Kabel digital tachometer.

9. Slot penahan roda depan.

10 . Body dynotest.
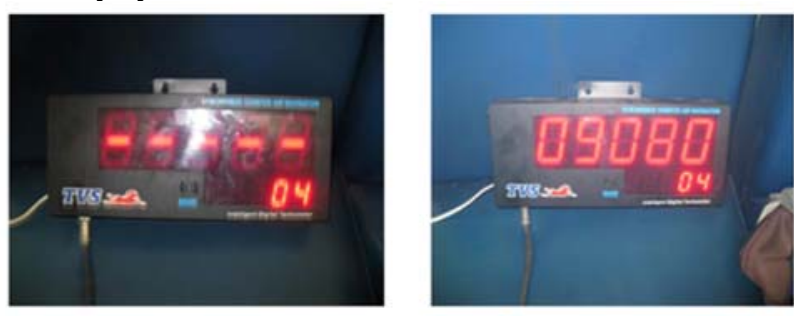

Gambar 4 Intelegent digital thachometer yang digunakan

Hasil analisa kemudian dibandingkan dengan kondisi standar untuk mengetahui perbedaan daya, torsi, fc, sfc, dan efisiensi termal yang selanjutnya disimpulkan.

\section{HASIL DAN DISKUSI}

Daya yang dihasilkan mesin setelah memperhitungkan beban dan putaran poros. Nilai daya pada mesin diperoleh setelah melalui proses pengujian. Pada gambar 5 hubungan daya terhadap putaran (rpm) terlihat perubahan durasi camshaft sangat mempengaruhi nilai daya yang diperoleh sehingga mempercepat tercapainya daya maksimum sebuah mesin. Pada mesin standar, daya pada putaran $8000 \mathrm{rpm}$ diperoleh sebesar 6,2 HP atau 4,63 kW sedangkan untuk mesin modifikasi pada putaran $8000 \mathrm{rpm}$ diperoleh daya sebesar 8,8 HP atau 6,56 kW. Menunjukkan selisih peningkatan daya mesin yang diperoleh dari camshaft standar dan modifikasi sebesar 2,6 HP atau 1,93 kW.

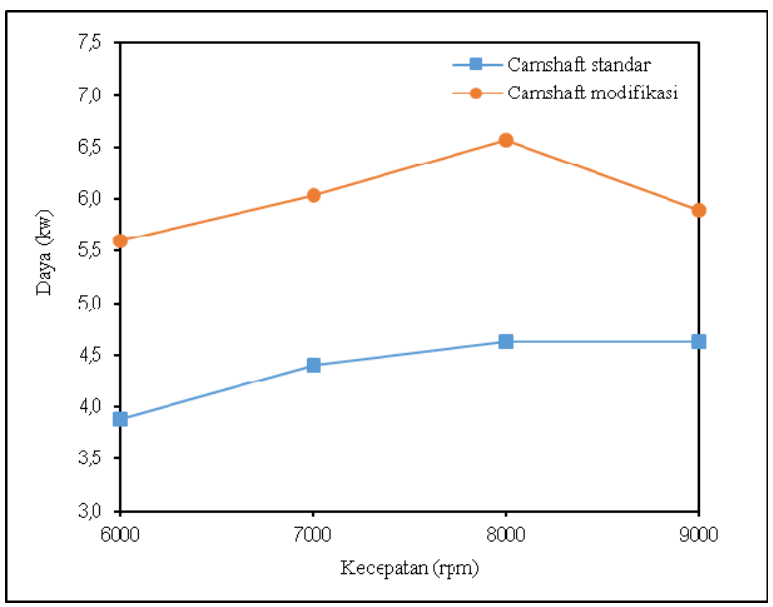

Gambar 5 Hubungan daya terhadap rpm
Pada gambar 6 terlihat perbedaan nilai torsi pada mesin modifikasi jika dibandingkan dengan mesin standar. Untuk mesin standar, torsi yang terjadi pada putaran $6000 \mathrm{rpm}$ sebesar $6,14 \mathrm{Nm}$ sedangkan untuk mesin modifikasi torsi pada putaran $6000 \mathrm{rpm}$ diperoleh nilai torsi sebesar 8,65 $\mathrm{Nm}$. Dengan demikian terjadi peningkatan dengan selisih torsi sebesar 2,51 Nm. Walaupun terjadi peningkatan torsi untuk mesin modifikasi namun akselerasi atau tarikan awal pada aktualnya berat bila dibandingkan dengan mesin standar.

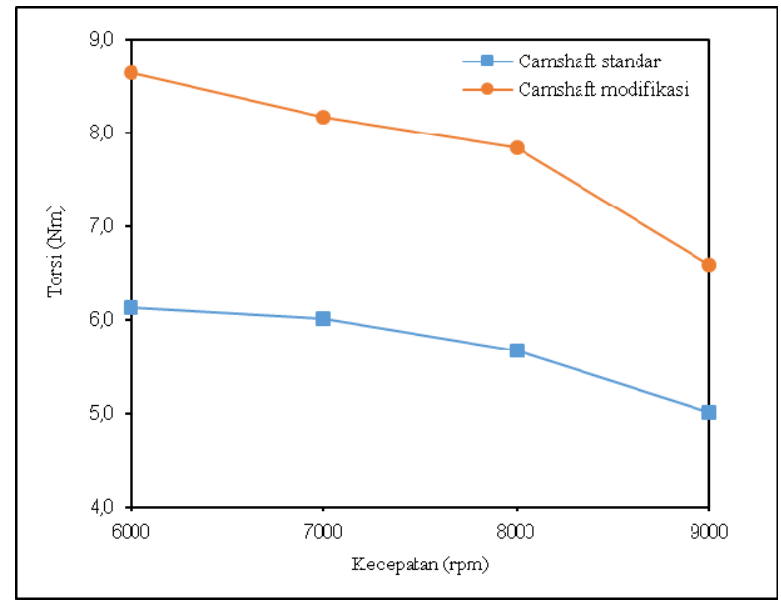

Gambar 6 Hubungan torsi terhadap rpm

Penggunaan bahan bakar merupakan sebuah kegunaan dari beberapa variabel, namun hanya putaran mesin yang akan diubah untuk mengetahui perubahan prestasi mesin. Semakin tinggi putaran mesin menyebabkan peningkatan penggunaan bahan bakar setiap menitnya, seperti tampak pada gambar 7 hubungan rpm dan fc, menunjukkan peningkatan fc untuk mesin yang telah dimodifikasi sebesar $0,883 \mathrm{~kg} / \mathrm{h}$ bila dibandingkan dengan mesin standar sebesar $0,653 \mathrm{~kg} / \mathrm{h}$. Peningkatan nilai fc pada mesin modifikasi disebabkan kerena sudut nose pada camshaft telah diperbesar sehingga durasi buka tutup katup akan menjadi cepat sehingga bahan bakar yang terhisap bersama udara cenderung bertambah.

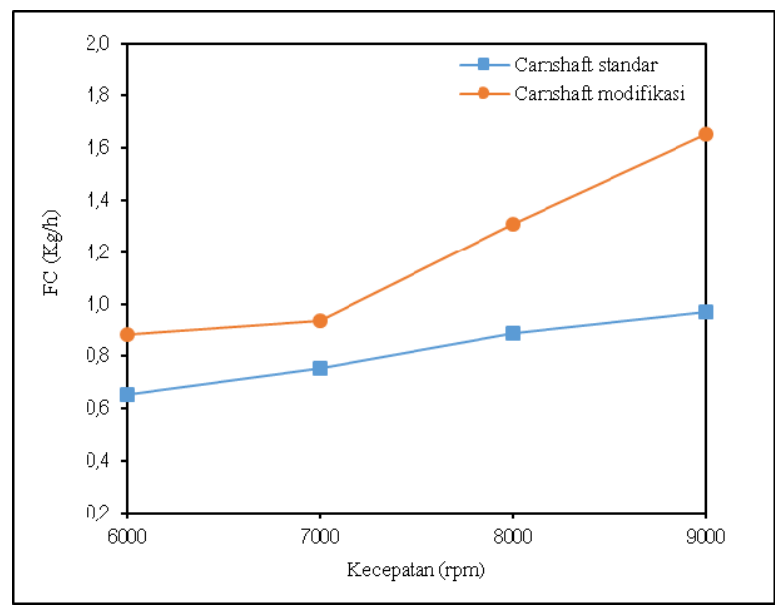

Gambar 7 Hubungan FC terhadap rpm 
Parameter ini yang dipakai sebagai ukuran ekonomis pada penggunaan bahan bakar yang dikonsumsi per jam untuk setiap daya kuda yang dihasilkan. Pada gambar 8 hubungan sfc terhadap rpm, nilai sfc untuk mesin modifikasi berada dibawah nilai mesin standar pada putaran $8000 \mathrm{rpm}$ kebawah. Namun terjadi peningkatan nilai sfc untuk mesin modifikasi pada saat putaran $8000 \mathrm{rpm}$ keatas sementara nilai yang diperoleh untuk kondisi standar pada putaran $8000 \mathrm{rpm}$ sebesar $0,192 \mathrm{~kg} / \mathrm{kWh}$ pada kondisi standar kemudian pada kondisi modifikasi sebesar $0,200 \mathrm{~kg} / \mathrm{kWh}$. Peningkatan nilai sfc pada mesin modifikasi disebabkan kerena sudut nose pada camshaft telah diperbesar sehingga durasi buka tutup katup akan menjadi cepat menyebabkan bahan bakar yang terhisap bersama udara cenderung bertambah dan menghasilkan daya yang besar dari pencampuran bahan bakar hasil pembakaran.

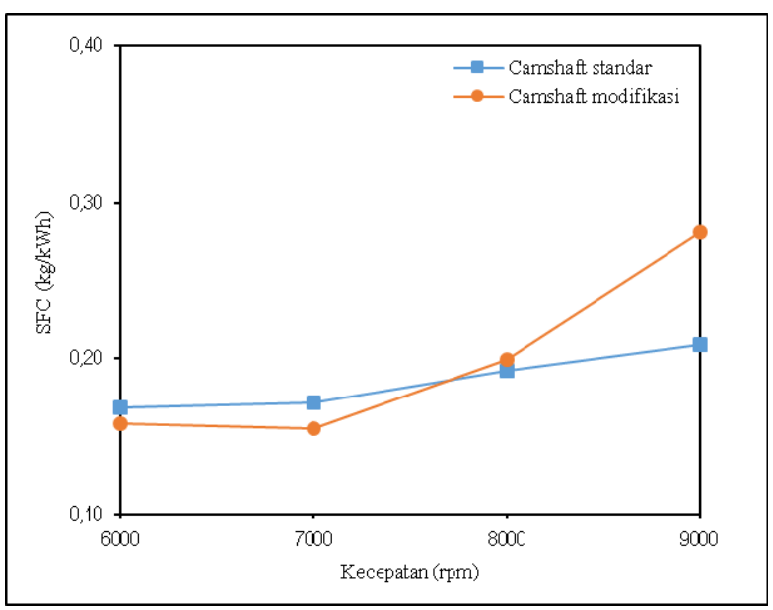

Gambar 8 Hubungan SFC terhadap rpm

Efisiensi termal suatu hal yang penting dalam motor bakar, untuk mengetahui banyaknya energi pada bahan bakar yang dikonversikan menjadi tenaga. Pada gambar 9 hubungan efisiensi termal terhadap rpm, dapat dilihat pada putaran 6000 rpm efisiensi termal pada keadaan mesin standar diperoleh sebesar 50,01 \% yang kemudian menurun secara signifikan pada putaran $9000 \mathrm{rpm}$ sebesar 40,29\%, sementara untuk kondisi modifikasi mengalami peningkatan pada putaran 6000 rpm sebesar 53,34 \% dan kemudian mengalami penurunan yang cukup besar dengan nilai 30,02\% dibandingkan dengan mesin pada kondisi standar dengan putaran yang sama, hal ini disebabkan karena efek kalor dari perubahan sudut camshaft relatif meningkat dengan bertambahnya putaran mesin

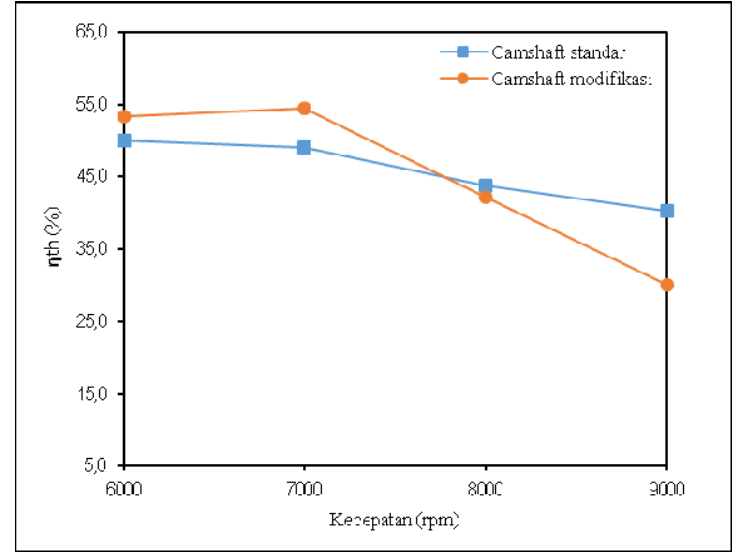

Gambar 9 Hubungan efisiensi termal terhadap rpm

Berikut tabel data perbandingan antara camshaft standar terhadap camshaft modifikasi

TABEL I DATA HASILPENGUJIAN DAN PERHITUNGAN CAMSHAFT STANDAR

\begin{tabular}{ccccccc}
\hline \multirow{2}{*}{ Rpm } & \multicolumn{2}{c}{ Daya } & Torsi & fc & sfc & nth \\
\cline { 2 - 7 } & HP & $\mathbf{k W}$ & $\mathbf{N m}$ & $\mathbf{k g} / \mathbf{h}$ & $\mathbf{k g} / \mathbf{k W h}$ & $\mathbf{\%}$ \\
\hline 6000 & 5,2 & 3,88 & 6,14 & 0,653 & 0,168 & 50,01 \\
7000 & 5,9 & 4,40 & 6,02 & 0,754 & 0,171 & 49,13 \\
8000 & 6,2 & 4.63 & 5,67 & 0,889 & 0,192 & 43,83 \\
9000 & 6,0 & 4.63 & 5,02 & 0,967 & 0,209 & 40,29 \\
\hline
\end{tabular}

TABEL II DATA HASIL PENGUJIAN DAN PERHITUNGAN CAMSHAFT MODIFIKASI

\begin{tabular}{ccccccc}
\hline \multirow{2}{*}{ Rpm } & \multicolumn{2}{c}{ Daya } & Torsi & fc & sfc & nth \\
\cline { 2 - 7 } & HP & $\mathbf{k W}$ & $\mathbf{N m}$ & $\mathbf{k g} / \mathbf{h}$ & $\mathbf{k g} / \mathbf{k W h}$ & $\mathbf{\%}$ \\
\hline 6000 & 7,5 & 5,60 & 8,65 & 0,883 & 0,158 & 53,34 \\
7000 & 8,1 & 6,04 & 8,18 & 0,934 & 0,155 & 54,43 \\
8000 & 8,8 & 6,56 & 7,85 & 1,311 & 0,200 & 42,15 \\
9000 & 7,9 & 5,89 & 6,60 & 1,653 & 0,280 & 30,02 \\
\hline
\end{tabular}

\section{KESIMPULAN}

Dari hasil pengujian yang dilakukan dapat ditarik beberapa kesimpulan, terjadi perubahan nilai daya dan torsi pada mesin yang telah diubah derajat camshaftnya. Untuk mesin standar, daya maksimumnya $6,2 \mathrm{HP}$ atau $4,63 \mathrm{~kW}$ dengan nilai torsi $5,67 \mathrm{Nm}$, sementara pada mesin modifikasi daya maksimumnya $8,8 \mathrm{HP}$ atau $6,56 \mathrm{~kW}$ dengan torsi maksimum 7,85 Nm. Dari data hasil pengujian diketahui bahwa terjadi peningkatan nilai daya dan torsi. Peningkatan daya sebesar 2,6 $\mathrm{HP}$ atau $1,94 \mathrm{~kW}$ kemudian peningkatan nilai torsi sebesar $2.18 \mathrm{Nm}$.

Selanjutnya terjadi perubahan nilai fc dan sfc pada mesin yang telah diubah derajat camshaft-nya. Perbedaan yang terjadi pada putaran mesin $9000 \mathrm{rpm}$. Untuk mesin standar, nilai $\mathrm{fc}=0,967 \mathrm{~kg} / \mathrm{h}$ dan nilai $\mathrm{sfc}=0,209 \mathrm{~kg} / \mathrm{kWh}$. Untuk mesin mesin modifikasi, nilai $\mathrm{fc}=1,653 \mathrm{~kg} / \mathrm{h}$ dan nilai $\mathrm{sfc}=$ $0,280 \mathrm{~kg} / \mathrm{kWh}$. Dengan demikian terjadi peningkatan nilai fc dan sfc pada mesin yang telah dimodifikasi. Peningkatan nilai fc dan sfc mesin modifikasi disebabkan kerena sudut nose camshaft telah diperbesar sehingga durasi buka tutup katup 
menjadi cepat akibatnya bahan bakar yang terhisap bersama udara cenderung bertambah.

\section{REFERENSI}

[1] Firman Iffah Darmawangsa dan Bambang Sudarmanta. 2016. Analisis Pengaruh Penambahan Durasi Camshaft Terhadap Unjuk Kerja Dan Emisi Gas Buang Pada Engine Sinjai $650 \mathrm{Cc}$. Jurnal Teknik ITS vol. 5 No. 1: 1-6. (online), (http://ejurnal.its.ac.id/index.php/teknik/article/view/15220).

[2] FX. Sukidjo. 2008. Pengaruh Durasi Camshaft terhadap Konsumsi Bahan Bakar, Emisi Gas Buang, Torsi dan Daya Mesin pada Mesin Bensin. Forum Teknik Vol. 32 No. 3: 210-220. (online), (http://i-lib.ugm.ac.id/jurnal/detail.php?dataId=12627)

[3] Dwi Kristianto, Margianto Margianto, Unung Lesmanah. 2014. Pengaruh Perubahan Durasi Camshaft Terhadap Performance Mesin Fd 110cc. Jurnal sains dan teknologi Teknik Mesin UNISMA vol. 3 no $2 . \quad$ (online), (http://riset.unisma.ac.id/index.php/jts/article/view/677).

[4] Octanius Dwi Prakoso dan Wahyudi. 2020. Pengaruh Penggunaan Variasi Camshaft Dengan Beda Durasi Terhadap Performa Mesin Sepeda Motor 4 Langkah. Automotive Science and Education Journal vol. 9 no $1 . \quad$ (online), (https://journal.unnes.ac.id/sju/index.php/asej/article/view/42198)

[5] Ardianto Argo Busono. 2010. Analisis Variasi Intake Manifold Standard dan Porting Pada Piston Standard dan Racing Terhadap Kinerja Sepeda Motor Honda GL100. Skripsi tidak diterbitkan. Surakarta: Universitas Muhammadiyah Surakarta.

[6] Hammil, Des. 1998. How To Choose Camshaft \& Time Them For Maximum Power. Veloce Publishing PLC. United Kingdom.

[7] Priyo Andrianto Stevansa. 2020. Pengaruh Penggunaan Camshaft Standard Dan Camshaft Racing Terhadap Unjuk Kerja Motor Bensin Empat Langkah. Skripsi tidak diterbitkan. Surakarta: Universitas Muhammadiyah Surakarta.

[8] Burgess, Peter, Gollan, David. 2000. How To Build, Modify And Power Tune Cylinder Head. Veloce Publishing PLC. United Kingdom.

[9] Wiranto Arismunandar. 2002. Motor Bakar Torak. Edisi Kelima Cetakan Kesatu. ITB Bandung.

[10] Bell, A. Graham. 2006. Four-Stroke Performance Tuning. Third Edition. J. H. Haynes \& Co., Ltd. Great Britain.

[11] Sugiarto. 2015. Modifikasi Sistem Bahan Bakar Karburator Menjadi Sistem Bahan Bakar Injeksi Pada Suzuki Smash Ad $2663 \mathrm{Zg}$ (Tinjauan Sistem Bahan Bakar). Proyek Akhir tidak diterbitkan. Yogyakarta: Universitas Negeri Yogyakarta.

[12] Laki, Rocky Fernando Gunawan, Hardi Gede, I Nyoman. 2013. Analisis Konsumsi Bahan Bakar Motor Bensin Yang Terpasang Pada Sepeda Motor Suzuki Smash 110 CC. Jurnal Online Poros Teknik Mesin, 1(1), 1-6. (online) (https://ejournal.unsrat.ac.id/index.php/poros/article/view/8169)

[13] Ahmad Thamrin D, Yusuf Siahaya dan Effendy Arif. 2016. Pengujian Prestasi Motor Bensin Berbahan Bakar Campuran Premium Dan Etanol Dari Nira Aren, Jurnal Ilmiah Techno Entrepreneur Acta, Vol.1 No.2 (online), (https://journal.unifa.ac.id/index.php/tea/article/view/12).

[14] M. Yusla. 2011. Kaji Pengaruh Subtitusi Ethanol Pada Solar Terhadap Kinerja Mesin Diesel Perkins (Tipe 4 - 108v). Skripsi tidak diterbitkan. Makassar: Universitas Hasanuddin.

[15] Albert Marganda Rumahorbo, Mulfi Hazwi. 2014. Analisa Eksperimental Performansi Mesin Diesel Menggunakan Bahan Campuran Biofuel Vitamine Engine Power Booster. Jurnal edinamis, Vol.9 No.1, (online), (https://garuda.ristekbrin.go.id/documents/detail/1432804). 